\title{
Approach to Impaired Liver Function Tests
}

\author{
Abdulwahed Al-Saeed, MD, SBIM ${ }^{1}$, Masoumah Redha Alawami, MBBS ${ }^{2}$ \\ ${ }^{1}$ Department of Medicine, Dammam Medical Complex. PO Box 6663, Alraih, Al-Qatif 32654-4839, Saudi Arabia. \\ ${ }^{2}$ Bachelor of Medicine/ Bachelor of Surgery.
}

\begin{abstract}
Initially, it is important to make distinction between liver function andliver enzyme which include, serum aminotransferases level and alkalinephosphatase level. Their elevations indicate hepatocyte and bile ductepithelial injury. However, albumin, bilirubin and prothrombin time are measures of hepatic function. But, these are affected by extrahepatic factors such as nutrition, hemolysis and antibiotic use.
\end{abstract}

Keywords: Liver function tests (LFTs); Aspartate transaminase (AST); Alanine aminotransferase (ALT); alkaline phosphatase (ALP); G Glutamyl transpeptidase (GGT).

\section{Introduction}

Standard laboratory tests for liver function are oftenrequested bydoctors in patients with non-specificsymptoms such as tiredness,abdominal pain, dyspepsia, and weight loss. Considerableuncertaintyexists asto the appropriate follow up of mildly abnormal resultsinpatients with no signs suggestive of liver disease. ${ }^{[1,2]}$

Aminotransferases are among the most wildly use test and notspecifically to the liver, althgh they are wildly use as liver enzymes.Aspartate transaminase (AST) is found in liver, muscle, heart,kidney, red cell and brain.Alanine aminotransferase (ALT) little more specific to the liver, and found in muscle and kidney. ${ }^{[1-3]} \mathrm{ALT}$ is thoughtto be more specific for hepatic injury becauseit is presentmainly in the cytosol of the liverand in low concentrations elsewhere. ASThas cytosolic and mitochondrial forms andis present in tissues of the liver, heart, skeletalmuscle, kidneys, brain, pancreas, andlungs, and in white and red blood cells. ASTis less commonly referred to as serum glutamicoxaloacetic transaminase and ALT asserum glutamic pyruvic transaminase. ${ }^{[1-3]}$

Blood tests commonly obtained to evaluate the health of the liver include liver enzyme levels alanine aminotransferase (ALT), aspartate aminotransferase (AST), alkaline phosphatase, gamma-glutamyl transferase), tests of hepatic synthetic function (albumin, prothrombin time/international normalized ratio (INR)), and the serum bilirubin level. ${ }^{[1-6]}$

The initial evaluation of a patient with abnormal liver biochemical and function tests (LFTs) includes obtaining a history to identify potential risk factors for liver disease and performing a physical examination to look for clues to the etiology and for signs of chronic liver disease. Subsequent testing is determined based on the information gathered from the history and physical examination as well as the pattern of LFT abnormalities. ${ }^{[1-6]}$

The child-Pugh score is perhaps the best indicator of liver function in patient with cirrhosis and MELD score measures more than liver function. ${ }^{[7-10]}$ The Child-Pugh score is still consideredthe cornerstone in the prognostic evaluation ofcirrhotic patients although it was formulated more than 30years ago. Nevertheless, it has some drawbacks such assubjectivity of clinical parameters and limited discriminateability. ${ }^{[7-10]}$ Child-Pugh class A patients usually show good mediumterm survival withoutorthotropic liver transplantation (OLT) unless other events (for example,hepatocellular carcinoma, uncontrolled bleeding due to portalhypertension, etc) occur, ${ }^{[10]}$ while Child-Pugh class $\mathrm{C}$ patientsare considered the conventional candidates for the procedure.Child-Pugh class B patients can be considered a heterogeneousgroup as their clinical condition may remain stable formore than a year or rapidly deteriorate. ${ }^{[7.11]}$

MELDscoring system is useful for predicting prognosis inpatients with liver cirrhosis and is correlated with residual liver function. It predictor of bothshort and medium term survival, and performs at least as well as the Child-Pugh score. An increase inMELD score is associated with a decrease in residual liver function. ${ }^{[12]}$ The Model for EndStage Liver Disease (MELD) consists of serum bilirubin and creatinine levels, International Normalized Ratio (INR) for prothrombin time, and etiology of liverdisease ${ }^{[12]}$ Recently, the model for end stage liver disease (MELD) wasintroduced as a tool to predict mortality risk and to assessdisease severity in patients with liver cirrhosis so as todetermine organ allocation priorities. ${ }^{[12]}$ Although previously formulated as a prognostic index for cirrhotic patientsundergoing transjugular intrahepatic portosystemic stentshunt (TIPSS), it was validated by the same authors on abroad series of patients with liver disease of various aetiologyand severity. ${ }^{[13,14]}$ Nevertheless, although the MELD score takesinto consideration objective parameters (serum creatinine, the international normalized ratio (INR), bilirubin levels)and is computed with statistically derived coefficients on acontinuous scale with no upper or lower limits, thus avoidingmany drawbacks of the Child-Pugh score, it has generatedsome criticism. ${ }^{[15,16]}$

\section{Properties}

Alanine aminotransferase (ALT) exclusively in cytoplasm whereas aspartate transaminase (AST), is both cytoplasm and mitochondrial. 


\section{International Journal of Science and Research (IJSR) \\ ISSN (Online): 2319-7064}

Index Copernicus Value (2013): 6.14 | Impact Factor (2015): 6.391

The half life of total AST is $17+/-5$ hours, whereas ALT is $47+/-10$ hour. AST/ALT ratio depend on gender, age and $\operatorname{sex}^{[3,17]}$

The aminotransferases (formerly transaminases)are themost frequently utilized and specific indicators ofhepatocellular necrosis. These enzymes- aspartateaminotransferase(AST, formerly serum glutamateoxaloacetic transaminase-SGOT) and alanine aminotransferase( ALT, formerly serum glutamic pyruvatetransaminase-SGPT) catalyze the transfer of the á aminoacids of aspartate and alanine respectively to the á ketogroup of ketoglutaric acid. ALT is primarily localized tothe liver but the AST is present in a wide variety of tissueslike the heart, skeletal muscle, kidney, brain and liver. ${ }^{[18,19]}$ Etiology of aminotransferase of non hepatic causes are hemolysis, myocardial infarction, acute renal injury, infracted bowel, brain injury, and macroenzymes. ${ }^{[20]}$

Alkaline phosphates are a family of zincmetaloenzymes, with a serine at the active center; theyrelease inorganic phosphate from various organicorthophosphates and are present in nearly all tissues. Inliver, alkaline phosphatase is found histochemically in themicrovilli of bile canaliculi and on the sinusoidal surfaceof hepatocytes. Alkaline phosphatase from the liver, boneand kidney are thought to be from the same gene but thatfrom intestine and placenta are derived from differentgenes. ${ }^{[20]}$

G Glutamyl transpeptidase(GGT) or 5nucleotidase can help hepatic vs. nonhepatic source because of elevatedparallel to alkaline phosphatase. Alkaline phosphatase elevated physiologically in whom less than 18 years old, or pregnant woman. ${ }^{[21]}$ ALP Largely originate from the liver, mainly cells lining biliary ducts or membranes adjoining the bile canaliculi, and bones Marked increase is typical of cholestasis (often with raised GGT) Variety of bone disorders (usually without raised GGT) Isoenzymes may be useful for distinguishing these sources. ${ }^{[21-29]}$ Gamma GT Found in the hepatocytes and biliary epithelial cells. Sensitive in detecting hepatobiliary disease but limited by lack of specificity Best used to evaluate elevation of other enzymes High GGT with otherwise normal liver should not lead to exhaustive work up for liver disease Twofold elevation with AST:ALT ratio2:1suggest alcohol abuse. $^{[1,2,30-35]}$

Albumin is synthesized in the liver Albumin has a plasma half-life of three weeks; therefore, serum albumin concentrations change slowly in response to alterations in synthesis. In practice, patients with low serum albumin concentrations and no other LFT abnormalities are likely to have a nonhepatic cause for low albumin, such as proteinuria or an acute or chronic inflammatory state. ${ }^{[1,2,30-35]}$

Albumin synthesis isaffected not only in liver disease but also by nutritionalstatus, hormonal balance and osmotic pressure. ${ }^{[20]}$ The serum levels are typically depressed in patientswith cirrhosis and ascites. In patients with or withoutascites, the serum albumin level correlates with prognosis. ${ }^{[36]}$ In addition the rate of albumin synthesis hasbeen shown to correlate with the Child- Turcotte orChild- Pugh score ${ }^{[37]}$ Corticosteroids and thyroid hormone stimulatealbumin synthesis by increasing the concentration ofalbumin mRNA and tRNA in hepatocytes. ${ }^{[38]}$ The serum albumin levels tend to be normal indiseases like acute viral hepatitis, drug relatedhepatotoxicity and obstructive jaundice.Albumin levelsbelow $3 \mathrm{~g} / \mathrm{dl}$ in hepatitis should raise the suspicion ofchronic liver disease like cirrhosis which usually reflectsdecreased albumin synthesis. In ascites there may benormal synthesis but the levels may appear reducedbecause of increased volume of distribution. ${ }^{[39,40]}$ Hypoalbuminemia is not specific for liver disease andmay occur in protein malnutrition, nephrotic syndromeand chronic protein losing enteropathies. ${ }^{[41]}$

Prothrombin time (PT) not usually included in the LFTs panel.Abnormal PT prolongation may be a sign of serious liver dysfunction. An elevated PT can result from a vitamin $\mathrm{K}$ deficiency ,a trial of vitamin $\mathrm{K}$ injections is the most practical way to exclude vitamin $\mathrm{K}$ deficiency in such patients. $^{[1,2,30-35]}$

The liversynthesizes both albumin and many of the blood coagulationfactors that are required to be in adequate concentrationsin order for the prothrombin time to be normal.Thus, in the absence of other nonhepatic etiologies forabnormalities in the albumin orprothrombin time, theselaboratory tests can be useful in assaying hepatic syntheticfunction. The half-life of serum albumin normallyis 19-21 days, whereas the half-life of blood coagulationfactors may be less than a day, so these tests often can beused in tandem to assess both acute and chronic componentsof hepatic function or impairment. The prothrombintime may be a better indicator of coagulation in liverdiseases than the international normalization ratio. ${ }^{[42-44]}$

Bilirubin is derived from the breakdown of haem in the red blood cells within the reticuloendothelial system.The unconjugated bilirubin then binds albumin and is taken up by the liver.In the liver, it is conjugated which then makes it water-soluble and thus allows it to be excreted into the urine.Normally total serum bilirubin is measured; however, the unconjugated and conjugated portions can be determined by measures of the fractions of indirect bilirubin and direct bilirubin respectively. ${ }^{[45]}$ The classificationof bilirubin into direct and indirect bilirubin are based onthe original van der Bergh method of measuringbilirubin. Bilirubin is altered by exposure to light so serum and plasmasamples must be kept in dark before measurements are made. ${ }^{[19]}$

Unlike serum liver chemistry tests like the serum ALT,AST, and alkaline phosphatase (which are not true indicatorsof hepatic function), serum albumin levels andprothrombin time, along with physical examinationfindings such as encephalopathy, are important clinicalparameters of hepatic function that are essential in thecontext of interpreting abnormal serum liver chemistrytests, especially in clinical scenarios of impendinghepaticfailure. ${ }^{[46,47]}$

\section{Patterns of Liver Disease}

The abnormal liver enzymes are charactrized by either acute or chronic of cutt off six month which is either hepatocllular or cholestatic or mixed. Injury to the liver, whether acute or chronic, eventually results in an increase in serum concentrations of aminotransferases. ${ }^{[1,48]}$ Based on the pattern 


\section{International Journal of Science and Research (IJSR) \\ ISSN (Online): 2319-7064}

Index Copernicus Value (2013): 6.14 | Impact Factor (2015): 6.391

of the serum liver chemistryabnormalities, serum liver chemistry tests can be classifiedto provide a practical approach for the evaluation anddiagnosis of hepatobiliary diseases. For the purpose ofthis document, we have classified the analysis of liverchemistry abnormalities to the interpretation of serumALT and aspartate aminotransferase (AST) abnormalities(hepatocellular injury) and serum alkaline phosphataseand bilirubin abnormalities (cholestatic pattern). Althoughit is important to emphasize that liver chemistrytest abnormalities frequently occur in overlapping patterns,presenting an obvious limitation to this type ofcategorized analysis, the division of liverchemistry testabnormalities into "hepatocellular injury" and"cholestatic"patterns allows a commonly used, simplified approachfor the interpretation of serum liver chemistries.In addition, elevations of the hepatic alkaline phosphatasewith minimal or no elevations of the serum ALT,AST, or bilirubin also may be indicative of "infiltrative"diseases of the hepatic parenchyma. Blood tests such asserum albumin and prothrombin time are also importantdeterminants of hepatic synthetic function, but are notspecific for hepatic disease. Nonetheless, these tests havean essential role in the evaluation of the hepatic functionof patients with acute or chronic liver diseases. ${ }^{[9-51]}$

Although levels of ALT and AST can beextremely elevated (exceeding 2,000 U per Lin cases of hepatocyte injury and necrosisrelated to drugs, toxins, ischemia, - related, herpes simplex virus, acetamiophenon, andhepatitis. Howevere, fatty liver, hemochromatosis and alfa one antitrypsin deficiency are the etiology of chronic liver.The both acute and chronic hepatitis etilology include autoimmune, Wilson's Disease, hepatitis B, Bud-chiari syndrome, alcoholic liver disease andmedication. The cause of extracholestatic liver diseaseare stone, cancer, sphinector dysfunction and choledochal cyst or trauma.The cause ofintracholestatic liver disease are primary biliary cirrhosis cholangitis, sepsis, drugs, granulomas, total parenteral nutrition, and metastases. While both intra and extracholestasis liver disease are primary sclerosing cholangitis, cholangiocarcinoma and radiation. ${ }^{[49-53]}$

\section{Clinical Value of Different Patterns \& Level}

In almost all liver disease, ALT is higher than AST except in alchoholic liver disease and advanced liver fibrosis. In alchoholic hepatitis, ASTis greater than ALT. Alchol increases mitochondrial AST and decrease cytoplasmic ALT. ALT is also low due to pyridoxine deficiency. ${ }^{[54]}$

AST and ALT are significantly lower inpatients with renal failure. ${ }^{[55]}$

Normal ALT in patients with hepatitis $\mathrm{C}$ virus (HCV) may still be associated with abnormal hepatic histology. ${ }^{[56]}$ Level less than 300U/L in chronic HCV/HBV, NAFLD and hemochromatosis. ${ }^{[57]} \mathrm{ALT}$ more than 150 or AST more than $300 \mathrm{U} / \mathrm{L}$ is uncommon in alcholic liver disease. ${ }^{[54]}$ Aminotransferase can be elevated in the contex of other abnormalities with raise bilirubin such as hemolysis, Gilbert's, and obstruction. In Wilson's will found very high level of aminotransferases and hemolysis. However, very high level of aminotransferases with new onset ascites found in cardiac or Budd-Chiari. Very high level of aminotransferases and $\mathrm{LDH}$ found in ischemic hepatitis, with high CPK in rhabdomyolysis. ${ }^{[58]}$ The ratio of AST to ALT has some clinicalutility, but has important limitations. In manyforms of acute and chronic liver injury or steatosis(fatty infiltration of the liver), the ratiois less than or equal to 1 . This is particularlytrue in patients with hepatitis C. However, anAST/ALT ratio greater than 2 characteristicallyis present in alcoholic hepatitis. A recent studyof 140 patients with nonalcoholic steatohepatitis(NASH; confirmed by liver biopsy) oralcoholic liver disease found a meanAST/ALTratio of 0.9 in patients with NASH and 2.6 inpatients with alcoholic liver disease. ${ }^{[58]}$ Withinthe population studied, 87 percent ofpatientswith an AST/ALT ratio of 1.3 or less had NASH(87 percent sensitivity, 84 percent specificity).The severity of NASH as measured bythe degree of fibrosis increased, as did theAST/ALT ratio. A mean ratio of 1.4 was foundin patients with cirrhosis related to NASH. ${ }^{[58]}$ Wilson's disease, a rare problem, can cause theAST/ALT ratio to exceed 4.5 While these ratiosare suggestive of certain conditions, there istoo much overlap between groups to rely onthem exclusively when making a diagnosis. ${ }^{[58]}$

The AST and ALT levels are increased to some extent in almost all liver diseases. The highest elevations occur in severe viral hepatitis, drug or toxin induced hepatic necrosis and circulatory shock. Although enzyme levels may reflect the extent of hepatocellular necrosis they do not correlate with eventual outcome. In fact declining AST and ALT may indicate either recovery of poor prognosis in fulminant hepatic failure. ${ }^{[19,20]}$

The AST and ALT aremoderately elevated in acute hepatitis, neonatal hepatitis,chronic hepatitis, autoimmune hepatitis, drug inducedhepatitis, alcoholic hepatitis and acute biliary tractobstructions. The ALT is usually more frequentlyincreased as compared to AST except in chronic liverdisease. In uncomplicated acute viral hepatitis, the very high initial levels approach normal levels within 5 weeksof onset of illness and normal levels are obtained in 8weeks in $75 \%$ of cases.For reasons, which are not, understood AST levelsappear disproportionately low in patients with Wilsondisease. ${ }^{[19,20]}$

The ratio of AST to ALT is of use in Wilson disease,chronic liverdisease(CLD)and alcoholic liver disease and a ratio of more than 2 isusually observed. The lack of ALT rise is probably due topyridoxine deficiency. In NASH the ratio is less than onein the absence of fibrosis on liver biopsy. ${ }^{[19]}$

In viral hepatitis the ratio is usually less than one. Theratio invariably rises to more than one as cirrhosisdevelops possibly because of reduced plasma clearance ofAST secondary to impaired function of sinusoidal cells. ${ }^{[59]}$ ALT exceeds AST in toxic hepatitis, viral hepatitis,chronic active hepatitis and cholestatic hepatitis. ${ }^{[20]}$

\section{Conclusion}

Liver biochemistries are among the most widely ordered test in clinical practice. Aminotrasferases and alkaline phosphatase are not liver function test. Patterns of their elevation are significant utility at the bedside.Finding the 


\section{International Journal of Science and Research (IJSR) \\ ISSN (Online): 2319-7064}

Index Copernicus Value (2013): 6.14 | Impact Factor (2015): 6.391

way through the multiple diagnostic pathways can challenge even the experienced clinician. Knowledge of the pathophysiology of liver enzymes is an essential guide to understanding their alteration. The pattern of enzyme abnormality, interpreted in the context of the patient's characteristics, can aid in directing the subsequent diagnostic work-up. Awareness of the prevalence of determined liver disease in specific populations and of possible hepatic involvement during systemic illnesses or drug therapies may help the clinician identify the cause of alterations efficiently. Child's score is most widely used for assessing the liver function.

\section{References}

[1] Dufour DR, Lott JA, Nolte FS, et al. Diagnosis and monitoringof hepatic injury. I. Performance characteristics of laboratorytests. Clin Chem 2000;46(12):2027-49.

[2] Dufour DR, Lott JA, Nolte FS, et al. Diagnosis and monitoring of hepatic injury. II. Recommendations for use of laboratory tests in screening, diagnosis, and monitoring. Clin Chem 2000;46(12):2050-68.

[3] Limdi JK, Hyde GM; Evaluation of abnormal liver functiontests. Postgrad Med J. 2003;79(932):307-12.

[4] Pratt DS, Kaplan MM. Evaluation of abnormal liverenzymeresults in asymptomatic patients. N Engl J Med 2000;342:1266.

[5] Wallis K, Price S, Gorard DA. Elevated liver enzymes in asymptomatic patients. $\mathrm{N}$ Engl J Med. 2000 31;343(9):662-3

[6] Rosalki SB, Dooley JS. Liver function profiles and their interpretation. Br J Hosp Med. 1994 1;51(4):181-6.

[7] Oellerich M, Burdelski M, Lautz HU, et al. Assessment of pre-transplant prognosis in patients with cirrhosis. Transplantation 1991;51:801-6.

[8] Testa R, Valente U, Risso D, et al. Can the MEGX test and serum bile acids improve the prognostic ability of Child-Pugh's score in liver cirrhosis? Eur J Gastroenterol Hepatol 1999;11:559-63.

[9] Shrescha R, McKinley C, Showalter R, et al. Quantitative liver function tests define the functional severity of liver disease in early-stage cirrhosis. Liver Transpl Surg 1997;3:166-73.

[10] Shiffman ML, Fisher RA, Sanyal AI, et al. Hepatic lidocaine metabolism and complications of cirrhosis. Implications for assessing patient priority for hepatic transplantation. Transplantation 1993;55:830-5.

[11] http://depts.washington.edu/hepstudy/mgmt/mgmt/ascit esMgmt/discussion.html

[12] Malinchoc M, Kamath PS, Gordon FD, et al. A model to predict poor survival in patients undergoing transjugular intrahepatic portosystemic shunts. Hepatology. 2000;31(4):864-71.

[13] Kamath PS, Wiesner RH, Malinchoc M, et al. A model to predict survival in patients with end-stage liver disease. Hepatology 2001;33:464-70.

[14] Forman LM, Lucey MR. Predicting the prognosis of chronic liver disease: an evolution from Child to MELD. Hepatology 2001;33:473-5.

[15] McCaughan GW, Strasser SI. To MELD or not to MELD? Hepatology 2001;34:215-16.
[16] Wiesner RH, McDiarmid SV, Kamath PS, et al. MELD and PELD: application of survival models to liver allocation. Liver Transpl 2001;7:567-80.

[17] Walsh K, Alexander G; Alcoholic liver disease. Postgrad Med J. 2000;76(895):280-6.

[18] Rosen HR, Keefe EB. Evaluation of abnormal liver enzymes, use of liver tests and the serology of viral hepatitis: Liver disease, diagnosis and management. 1st ed. New York; Churchill livingstone publishers, 2000; 24-35.

[19]Friedman SF, Martin P, Munoz JS. Laboratory evaluation of the patient with liver disease. Hepatology, a textbook of liver disease. Philedelphia; Saunders publication, 2003; $1:$ 661-709.

[20] Rosalki SB, Mcintyre N. Biochemical investigations in the management of liver disease. Oxford textbook of clinical hepatology, 2nd ed. New York; Oxford university press, 1999; 503-521.

[21] Moss DW. Physiochemical and pathophysiological factors in the release of membrane-bound alkaline phosphatase from cells. Clin Chim Acta 1997;257 (1):133-40.

[22] Schlaeger R, Haux D, Kattermann R. Studies on the mechanism of the increase in serum alkaline phosphatase activity in cholestasis: significance of the hepatic bile acid concentration for the leakage of alkaline phosphatase from rat liver. Enzyme 1982;28(1):3-13.

[23] Velayudham LS, Farrell GC. Drug-induced cholestasis. Expert Opin Drug Saf 2003;2(3):287-304.

[24] Ponsioen CI, Tytgat GN. Primary sclerosing cholangitis: a clinical review. Am J Gastroenterol 1998;93(4):515-23.

[25] Heathcote J. Update on primary biliary cirrhosis. Can J Gastroenterol 2000;14 (1):43-8.

[26] Poupon R. Autoimmune overlapping syndromes. Clin Liver Dis 2003;7(4):865-78.

[27] Bonnand AM, Heathcote EJ, Lindor KD, et al. Clinical significance of serum bilirubin levels under ursodeoxycholic acid therapy in patients with primary biliary cirrhosis. Hepatology 1999;29(1):34-43.

[28] Kim WR, Therneau TM, Wiesner RH, et al. A revised natural history model for primary sclerosing cholangitis. Mayo Clin Proc 2000;75(7):688-94.

[29] Doumas BT, Peters T. Serum and urine albumin: a progress report on their measurement and clinical significance. Clin Chim Acta 1997;258(1):3-20.

[30] Pugh RN, Murray-Lyon IM, Dawson JL, et al. Transection of the oesophagus for bleeding oesophageal varices. Br J Surg 1973;60(8): 646-9.

[31] Bonis PA, Tong MJ, Blatt LM, et al. A predictive model for the development of hepatocellular carcinoma, liver failure, or liver transplantation for patients presenting to clinic with chronic hepatitis C. Am J Gastroenterol 1999;94(6):1605-12.

[32] Kamath PS, Wiesner RH, Malinchoc M, et al. A model to predict survival in patients with end-stage liver disease. Hepatology 2001;33(2):464-70.

[33] Botta F, Giannini E, Romagnoli P, et al. MELD scoring system is useful for predicting prognosis in patients with liver cirrhosis and is correlated with residual liver function: a European study. Gut 2003;52(1):134-9. 


\section{International Journal of Science and Research (IJSR) \\ ISSN (Online): 2319-7064}

Index Copernicus Value (2013): 6.14 | Impact Factor (2015): 6.391

[34] Jalan R, Hayes PC. Review article: quantitative tests of liver function. Aliment Pharmacol Ther 1995;9(3):26370.

[35] Mizuno A, Uematsu T, Gotoh S et al. The measurement of caffeine concentration in scalp hair as an indicator of liver Disease 1996; 48 : 660-665.

[36] Anderson GF, Barnhart MI. intracellular localization of prothrombin. Proc Soc Exp Biol Med 1964; 116 : 1-4.

[37] Jefferson DM Reid LM, Giambrone MA, et al. Effects of dexamethasone on albumin and collagen gene expression in primary cultures of adult rat hepatocytes. Hepatology 1985; 5 : 14-19.

[38] Rothschild MA, Rothschild MA, Oratz M, et al. Albumin synthesis in cirrhotic subjects studied with carbonate 14 C. J Clin Invest 1969; 48 : 344-349.

[39] Hasch E, Murray Oratz, David Zimmon, at al. Albumin synthesis rate as a measure of liver function in patients with cirrhosis. Arch Intern Med 1967; 182 :38-44.

[40]Daniel SP, Marshall MK. Evaluation of the liver: laboratory tests. Schiff's diseases of the liver, 8th edn. USA; JB Lippincott publications, 1999; 205-239.

[41] Ts'ao C, Swedlund J, Neofotistos D. Implications of use of lowinternational sensitivity index thromboplastins in prothrombintime testing. Arch Pathol Lab Med 1994;118:1183-1187.

[42] Kovacs MJ, Wong A, MacKinnon K, et al. Assessment of the validity of the INR system for patients with liver impairment. Thromb Haemost 1994;71:727-730.

[43] Robert A, Chazouilleres O. Prothrombin time in liver failure: time, ratio, activity percentage, or international normalized ratio? Hepatology 1996;24:1392-1394.

[44] Giannini EG, Testa R, Savarino V; Liver enzyme alteration: a guide for clinicians. CMAJ. 2005 1;172(3):367-79.

[45]Lee WM. Acute liver failure. $N$ Engl J Med 1993;329:1862-1872.

[46] Harrison PM, O'Grady, Keays RT, et al.Serial prothrombin time as prognostic indicator in paracetamolinduced fulminant hepatic failure. BMJ 1990;301:964-966.

[47] Vanderlinde RE. Review of pyridoxal phosphate and the transaminases in liver disease. Ann Clin Lab Sci 1986;16(2):79-93.

[48] Roberts EA, Schilsky ML; Diagnosis and treatment of Wilson disease: an update American Association for Study of Liver Diseases (AASLD). Hepatology. 2008;47(6):2089-111

[49]EASL Clinical Practice Guidelines: Wilson's disease. European Association for Study of Liver. J Hepatol. 2012;56(3):671-85

[50] Green RM, Flamm S.AGAtechnicalreview on the evaluation of liver chemistry tests. Gastroenterology. 2002;123(4):1367-84.

[51] http://www.aasld.org/patients/Pages/KnowYourALT.as $\mathrm{px}$

[52] Giboney PT. Mildly elevated liver transaminase levels in the asymptomatic patient.Am Fam Physician. 2005;15;71(6):1105-

[53] EASLclinicalpracticalguidelines: management of alcoholic liver disease.J Hepatol. 2012;57(2):399-420.

[54]Hung KY, Lee KC, Yen CJ, et al.Revised cutoff values of serum aminotransferase in detecting viral hepatitis among CAPD patients: experience from Taiwan, an endemic area for hepatitis B. Nephrol Dial Transplant. 1997;12(1):180-3.

[55] Puoti C, Bellis L, Guarisco R, et al. HCV carriers with normalalanine aminotransferase levels: healthy persons or severely ill patients? Dealing with an everyday clinical problem. Eur J Intern Med. 2010 ;21(2):57-61.

[56] Bacon BR, Adams PC, Kowdley KV, et al.Diagnosis and managementofhemochromatosis: 2011practiceguideline by the AmericanAssociation for the StudyofLiverDiseases. Hepatology. 2011;54(1):32843.

[57] Sorbi D, Boynton J, Lindor KD. The ratio of aspartate aminotransferase to alanine aminotransferase: potential value in differentiating nonalcoholic steatohepatitis from alcoholic liver disease. Am J Gastroenterol 1999;94:1018-22.

[58] Park GJH, Lin BPC, Ngu MC et al. Aspartate aminotransferases: alanine aminotransferases ratio in chronic hepatitis $\mathrm{C}$ infection : is it a predictor of cirrhosis? 2000; $15: 386-389$. 